\title{
EL DESCONOCIMIENTO DEL SISTEMA DE FUENTES \\ EN DERECHO INTERNACIONAL PRIVADO RESPECTO LA COMPETENCIA JUDICIAL INTERNACIONAL A PROPÓSITO DE LA SENTENCIA DE LA AUDIENCIA PROVINCIAL DE VALENCIA DE 10 DE OCTUBRE DE 2020
}

\author{
THE LACK OF KNOWLEDGEMENT OF THE SYSTEM \\ OF SOURCES IN PRIVATE INTERNATIONAL LAW \\ RESPECTING INTERNATIONAL JURISDICTION IN RELATION \\ TO THE JUDGMENT OF THE VALENCIA PROVINCIAL COURT \\ OF 10 OCTOBER 2020
}

\author{
Pablo Melgarejo Cordón \\ Becario de Iniciación a la investigación \\ Universidad de Granada
}

Recibido: 15.06.2021 / Aceptado: 20.07.2021

DOI: https://doi.org/10.20318/cdt.2021.6298

\begin{abstract}
Resumen: La sentencia que es objeto de análisis estima un recurso de apelación contra un auto de instancia mediante el que el juez a quo se declara incompetente para conocer de la demanda. La actora presentó demanda para la regulación de la guarda, el régimen de comunicación y los alimentos del hijo, nacido en el año 2007, que tenía en común con el demandado. La Audiencia provincial de Valencia estima el recurso, y luego de realizar algunos apuntes sobre la nacionalidad de los interesados, así como sobre su residencia habitual, declara competentes a los tribunales españoles para conocer sobre del proceso sobre responsabilidad parental y sobre la reclamación de alimentos revocando el auto de instancia.

Palabras clave: Responsabilidad parental, alimentos, nacionalidad, residencia habitual, Reglamento 4/2009.

Abstract: The judgment under consideration estimates an appeal against an order of first instance by which the judge had declared himself incompetent to hear the application. The plaintiff filed a lawsuit concerning the regulation of the custody, communication regime and maintenance of the child, born in 2007, which she had in common with the defendant. The Provincial Court of Valencia considers the appeal, and after making some notes on the nationality of the interested parties, as well as on their habitual residence, declares the Spanish courts competent to hear proceedings relating to parental responsibility and the recovery of maintenance revoking the order of instance.
\end{abstract}

Keywords: parental responsibility, maintenance, nationality, habitual residence, Regulation 4/2009.

Sumario: I. Antecedentes de hecho, la decisión de instancia y contenido general del fallo. II. Cuestiones de Derecho internacional privado: 1. Competencia judicial internacional. 2. La residencia habitual como foro idóneo. 3. La prorrogatio fori como singularidad del Reglamento 4/2009. III. Conclusiones. 


\section{Antecedentes de hecho y decisión de instancia y contenido general del fallo}

1. El día 1 de junio de 2020, el Juzgado de Primera instancia $n^{\circ} 26$ de Valencia dictó auto por el que se declaraba incompetente para conocer sobre una demanda para la regulación de la guarda, el régimen de comunicación y los alimentos del hijo. En este orden refirió expresamente: "Acuerdo que este tribunal se abstenga del conocimiento de la demanda presenta por $D^{a}$ Nicolasa frente a $D$. Everardo por falta de competencia internacional".

2. El auto fue recurrido en apelación por la representación legal de la demandante ante la Audiencia Provincial de Valencia. Al ser remitidas las actuaciones a la Audiencia, se evidencia que el menor reside en Colombia con su bisabuela materna y que tanto demandante como demandado residen en España. A su vez, la demandante señala que el hijo de los litigantes adquirió la nacionalidad española.

3. La Audiencia, alejándose del criterio de instancia, indica que el Reglamento $n^{\circ} 2201 / 2003^{1}$ no resulta aplicable al presente caso dado que el menor no reside en un Estado miembro de la Unión Europea a tenor de lo dispuesto en el art. 8 de este instrumento normativo.

4. En este mismo sentido, la Audiencia refiere que es aplicable el Convenio de la Haya de 19 de octubre de 1996 relativo a la competencia, la ley aplicable, el reconocimiento, la ejecución y la cooperación en materia de responsabilidad parental y de medidas de protección de los niños ${ }^{2}$, pero que no atribuye competencia a los tribunales españoles.

5. Con base a lo anterior, la Audiencia entiende que es necesario acudir a la Ley Orgánica del Poder Judicial, concretamente al art. 22 quáter-d) para atribuir competencia a los tribunales españoles toda vez que la demandante es española y reside de forma habitual en España.

6. El órgano que conoce la apelación, indica que los tribunales españoles también ostentan competencia judicial internacional para conocer de la reclamación de alimentos con base al art. 3 letra a) del Reglamento 4/20093. El foro del art. 3 letra a) del Reglamento 4/2009 atribuye competencia al órgano jurisdiccional del lugar donde el demandado tenga su residencia habitual, esto es, España como se refirió anteriormente.

7. Por todo lo señalado supra la Sala acuerda: 1) estimar el recurso de apelación de la actora contra el auto de instancia; 2) revocar el auto mencionado y declarar competente al Juzgado de $1^{\mathrm{a}}$ Instancia de Valencia; 3) no imponer costas a ninguna de las partes.

\section{Cuestiones de derecho internacional privado}

8. Tal como se refirió anteriormente, la interposición del recurso por parte de la actora contra el auto da lugar a un proceso ante el órgano judicial jerárquicamente superior en el que se comprueba la competencia judicial internacional del Juzgado de Primera Instancia.

\footnotetext{
${ }^{1}$ Reglamento (CE) n n $^{\circ} 201 / 2003$ del Consejo, de 27 de noviembre de 2003, relativo a la competencia, el reconocimiento y la ejecución de resoluciones judiciales en materia matrimonial y de responsabilidad parental (Bruselas II bis), (DOUE L 338, de 23 de diciembre de 2003, páginas 1 a 29).

2 Convenio de la Haya de 19 de octubre de 1996 relativo a la competencia, la ley aplicable, el reconocimiento, la ejecución y la cooperación en materia de responsabilidad parental y de medidas de protección de los niños, (BOE núm. 291, de 2 de diciembre de 2010, páginas 1 a 32).

${ }^{3}$ Reglamento (CE) no 4/2009 del Consejo, de 18 de diciembre de 2008, relativo a la competencia, la ley aplicable, el reconocimiento y la ejecución de las resoluciones y la cooperación en materia de obligaciones de alimentos (Bruselas III), (DOUE L 7, de 10 de enero de 2009, páginas 1 a 79).
} 
9. Cuando la Audiencia examina la competencia judicial internacional del juez a quo se hacen visibles los fallos del auto por el que se declaraba la incompetencia del primer tribunal. Este aspecto de la competencia judicial internacional, junto a la presunta idoneidad del criterio de la residencia habitual, así como la prorrogatio fori como singularidad del Reglamento 4/2009 constituirán el objeto del presente comentario.

\section{La competencia judicial internacional}

10. El Juzgado de Primera Instancia despacha el asunto declarándose incompetente a través de auto sin un aparente examen del sistema de foros recogidos en el ordenamiento jurídico español.

11. Sensu contrario, la Audiencia Provincial examina todos los instrumentos normativos que tienen vocación de ser aplicados. Así, en primer lugar, la Audiencia indica que el Reglamento 2201/2003 no resulta aplicable al caso ya que el menor no tiene su residencia habitual en ningún Estado miembro de la UE. No obstante, como se verá más adelante, concretamente en el punto 2, la determinación de la residencia habitual requiere un examen más profundo y detenido. De los antecedentes de hecho puede entenderse a priori que el menor tiene su residencia habitual en Colombia y que por ello no puede ser aplicado al presente supuesto.

12. En segundo lugar, la Audiencia alude al Convenio de la Haya de 1996 sobre responsabilidad parental, sin embargo, yerra al considerar que resulta aplicable y considerar que no atribuye competencia. Para que este instrumento resulte aplicable es necesario que el menor tenga su residencia habitual en algún Estado parte. Dado que el menor reside en Colombia, tercer Estado que no ha ratificado el Convenio, no resulta aplicable a este supuesto en ninguna circunstancia.

13. En tercer lugar, de una u otra manera, se aterriza en la Ley Orgánica del Poder Judicial para atribuirle competencia a los órganos judiciales españoles, a través del art. 22 quáter-d) que utiliza la residencia habitual del demandante. En este caso, tal como se deduce de los antecedentes de hecho, la actora residía en España y, por tanto, los tribunales españoles eran competentes para conocer la demanda que se les había planteado.

14. En cuarto lugar, la Audiencia señala que en lo relativo a la reclamación de alimentos para el menor los órganos judiciales españoles también son competentes según lo dispuesto en el art. 3 letra a) del Reglamento 4/2009 puesto que el demandado reside habitualmente en España. Además, si se atiende a lo dispuesto en la letra d) del mismo precepto, los tribunales españoles que conozcan de una acción sobre responsabilidad parental conocerán también de la reclamación de alimentos.

15. En última instancia se observa que la competencia judicial internacional en materia de responsabilidad parental viene otorgada a los tribunales españoles por la Ley Orgánica del Poder Judicial, es decir, por el Derecho autónomo, mientras que en materia de alimentos será el Reglamento 4/2009 el que otorgue la competencia a los órganos jurisdiccionales españoles. Es preciso no olvidar que la acción de los alimentos es accesoria a la acción de responsabilidad parental.

16. En definitiva, puede apreciarse en este caso cómo la determinación de la competencia judicial internacional reviste cierta complejidad ya que es sustancialmente diferente a la competencia judicial interna ${ }^{4}$. De forma muy sutil, la Audiencia reprende al Juzgado de Primera Instancia su ineficacia a la hora de determinar la competencia judicial internacional. Una lectura detenida del caso muestra cómo la Audiencia ha de asumir la labor que le corresponde al juez a quo y que debiera haber realizado, que no

4 Vid. en este sentido: FERnÁNDEZ ROZAS, J.C. y SÁNCHEZ LOREnZo, S., Derecho internacional privado, $10^{\mathrm{a}}$ edic., Cizur Menor, Civitas-Thomson-Reuters, 2020 pp. 27 y 28. 
es sino repasar los distintos niveles de foros, a saber, institucional, convencional y autónomo, para acabar determinando si los órganos judiciales españoles eran competentes o no para conocer el asunto.

\section{La residencia habitual como foro idóneo}

17. La residencia habitual es un criterio de competencia que se utiliza en numerosos instrumentos normativos para determinar al tribunal competente, incluso para indicar la ley que resulte aplicable a la situación jurídica que se trate. La residencia habitual se ve revestida por un carácter "líquido", significando ello que la residencia habitual puede mutarse de forma más rápida y sencilla que, por ejemplo, la nacionalidad.

18. En un mundo cada día más globalizado, junto a la libre y vertiginosa circulación de ciudadanos en la UE, se hacen necesarios criterios veloces que se amolden a la rapidez de las relaciones jurídicas transfronterizas. Esta es una de las razones por las que la residencia habitual parece ser un foro adecuado para la regulación de aspectos en materia de familia.

19. Otra de las ventajas de la residencia habitual es que la futura sentencia será más fácil de ejecutar en el Estado en el que el demandado resida, pues será el Estado en el que posea bienes. En este supuesto concreto, en caso de impago de la obligación alimenticia la ejecución será ejecutada de forma directa.

20. Una ventaja añadida es que la residencia habitual, al contrario que la nacionalidad, es única, descartando así la posibilidad de dobles o varias residencias habituales. Ello supone un plus de seguridad jurídica. Así lo refiere expresamente el Abogado General del TJUE en el Asunto (C-80/19) ${ }^{6}$ : “...la residencia habitual es, como regla, el «nexo general» para determinar la competencia judicial internacional y la ley aplicable. Esa residencia, a mi juicio, solo puede ser una, no múltiple". Y así lo corrobora la sentencia de este asunto: "La autoridad que sustancia la sucesión debe fijar en uno solo de dichos Estados miembros la última residencia habitual del causante, en el sentido de dicho Reglamento."7. No obstante, puede suponer una desventaja en aquellos supuestos en los que la persona tenga una residencia habitual inestable al cambiar asiduamente de residencia habitual.

21. Desde un punto de vista procesal, como norma general, los litigantes verán reducidos los gastos que se deriven del proceso, al contrario que si se encontrasen inmersos en un proceso internacional en el que se acrecentarían indudablemente los costes de la litigación internacional.

22. Desde un punto de vista sustantivo, la parte más débil económicamente verá facilitado su acceso a la justicia.

23. Es cierto, no obstante, que a la residencia habitual se le pueden objetar algunas críticas como que su determinación, en muchas ocasiones, puede ser óbice para su operatividad. Dicho de otro modo, la residencia habitual de una persona no siempre será sencilla de establecer. No existe un "carnet de residencia habitual" ni un registro de la misma, al contrario de lo que ocurre con la nacionalidad que cuenta con mayores medios de prueba.

24. Otra crítica formulada a la residencia habitual tiene que ver con la posibilidad de que una persona carezca de residencia habitual y que este criterio no devenga operativo, aunque lo cierto es que la mayoría de personas físicas tienen residencia habitual en algún Estado.

\footnotetext{
5 Vid. CARRASCOSA GONZÁLEZ, J., "Reglamento sucesorio europeo y residencia habitual del causante" Cuadernos de Derecho Transnacional, 2016, vol. 8, núm. 1 pp. 48 a 50.

${ }^{6}$ Conclusiones Abogado General 26 de marzo de 2020, asunto C-80/19, Caso WB.

${ }^{7}$ Es cierto que esta sentencia se refiere a un asunto de sucesiones, pero el criterio de unidad de la residencia habitual puede ser extrapolado al concepto general.
} 
25. También puede pensarse, y no sin razón, que los tribunales en mejor posición para conocer del asunto serían los tribunales con los que las partes interesadas se encuentren más vinculados. Este criterio suele ser utilizado de forma subsidiaria como ocurre en el art. 21.2 sobre determinación de la ley aplicable en el Reglamento 650/2012 .

26. La utilización de la nacionalidad como foro ya ha quedado desplazada en la mayoría de instrumentos normativos modernos a un tercer plano por ser un criterio injusto ${ }^{9}$, anticuado y que pudiera ser hasta incoherente. Es muy posible que una persona no manifieste ningún tipo de relación con el Estado del que es nacional, de ahí que la nacionalidad pueda ser considerada inclusive como un "criterio de desconexión".

27. La conclusión que puede extraerse de este punto, es que a pesar de algunas desventajas que han sido analizadas brevemente sobre la residencia habitual, es este el criterio que goza de mayor idoneidad para actuar como foro de competencia.

\section{La prorrogatio fori como singularidad del Reglamento 4/2009}

28. El art. 4 del Reglamento 4/2009 permite a las partes elegir por escrito y con carácter exclusivo, salvo pacto en contrario, al Tribunal del Estado miembro que resolverá los litigios en materia de obligaciones de alimentos que se susciten entre las partes. Este mismo precepto es el que se encarga de limitar los Tribunales que pueden ser elegidos, señalando únicamente como elegibles a los Tribunales del Estado de la residencia habitual o de la nacionalidad de cualquiera de las partes.

29. Es cierto que esta misma operación de acuerdo de elección de fuero es extensible para los cónyuges y excónyuges a los órganos jurisdiccionales que sean competentes para conocer de la causa matrimonial, a través del Reglamento Bruselas II o a los de su última residencia habitual.

30. A pesar de lo anterior, en este supuesto concreto, no cabe plantearse la prorrogatio fori toda vez que la sumisión expresa a un tribunal solo podrá operar cuando se trate de obligaciones alimenticias respecto de mayores de 18, tal como reza el art. 4.3 del Reglamento 4/2009 ${ }^{10}$.

31. El sentido de incluir la prorrogatio fori descansa sobre la base de que este Reglamento pretende aumentar la seguridad jurídica ${ }^{11}$, pues serás los interesados los que hayan designado al Tribunal, la previsibilidad, ya que las partes sabrán en todo momento a qué órgano jurisdiccional acudir, y la autonomía de las partes, porque les permite diseñar el proceso en caso de litigio. Sin embargo, la inmensa mayoría de los legisladores, tanto nacional como comunitario, coinciden en la importancia de la protección prioritaria del más débil, en este caso el menor de 18 años. De ahí que se excluya la elección de foro en obligaciones alimenticias respecto de menores de 18 años. Con distintas nomenclaturas entre los Estados miembros, pero con la misma esencia, el interés superior del menor goza de prioridad respecto de la autonomía de la voluntad de las partes.

8 Reglamento 650/2012 del Parlamento Europeo y del Consejo de 4 de julio de 2012 relativo a la competencia, la ley aplicable, el reconocimiento y la ejecución de las resoluciones, a la aceptación y la ejecución de los documentos públicos en materia de sucesiones mortis causa y a la creación de un certificado sucesorio europeo, (Bruselas IV), DOUE L 201, de 27 de julio de 2012, páginas 107 a 134.

9 Vid. en este sentido: A.Bonomi, "Testamentary freedom or forced heirship? Balancing party autonomy and the protection of family members", Nederlands Internationaal Privaatrech, 2010, pp. 605-610.

10 Vid. A.L.Calvo Caravaca/J. Carrascosa González,Derecho Internacional Privado, Granada, Comares, $18^{a}$ ed., 2018, vol. II, pp. 544 a 547.

11 Vid. S.Álvarez GonzÁlez, El Reglamento 4/2009 CE sobre obligaciones alimenticias: cuestiones escogidas, Revista Jurídica Española La Ley, núm. 7230, de 31 de julio de 2009 pp. 74 a 78. 
32. A pesar de que en este caso concreto no resulte aplicable, la elección de foro es una de las mejores opciones con las que cuentan las personas físicas para evitar inconvenientes en este sentido en un proceso ulterior. Para que la elección sea adecuada habría de ser informada, es decir, puede ocurrir que los interesados desconozcan que la elección de los tribunales del Estado en el que residen supondrá mayores gastos derivados del litigio que si escogen $a d$. ex. a los órganos judiciales del Estado del que son nacionales, o a la inversa.

33. Otra ventaja de la elección del foro es que como regla general habrá una coincidencia forumius, significando ello que los tribunales aplicarán su propia ley nacional. En consecuencia, supondrá un ahorro en todos los aspectos del proceso (no habrá de probarse el Derecho extranjero, no se aplicarán normas extranjeras que normalmente serán menos conocidas por el tribunal, etc.). Todo apunta a que la actividad jurisdiccional que desarrolle el tribunal será de mayor calidad al aplicar su propio Derecho que si aplica el extranjero.

34. En suma, la prorrogatio fori no resulta aplicable a la sentencia que se analiza, sin embargo, ha podido comprobarse que es un instrumento útil y necesario que fomenta y favorece la seguridad jurídica, la previsibilidad y la autonomía de la voluntad de las partes, siempre limitada por la protección del menor.

\section{Conclusiones}

35. Esta sentencia es una prueba más de que el Derecho internacional privado sigue siendo una rama del ordenamiento jurídico parcialmente desconocida para un porcentaje destacable de los operadores jurídicos. El desconocimiento del Derecho internacional privado, y el sistema de fuentes de Derecho internacional privado en este caso implica inevitablemente la ignorancia de una parte esencial del ordenamiento jurídico español.

36. Es preciso no dejar de recordar que los reglamentos, directivas, decisiones y los convenios internacionales que España ratifique forman parte del ordenamiento jurídico español de igual manera que lo forma el Código civil. De hecho, podría afirmarse que despliegan una mayor importancia puesto que se aplican con preferencia a la normativa interna. Prueba de ello es la ya más que conocida sentencia Costa-Enel de 1964 en la que se garantizaba la superioridad del Derecho europeo sobre los Derechos nacionales, siendo este una de las claves de bóveda para el camino que tenía por recorrer la UE.

37. El juez a quo, demuestra en el auto en el que declara su falta de competencia un desconocimiento severo de las fuentes de Derecho internacional privado. Un análisis más detenido encamina a que esta situación provoca una ralentización en el funcionamiento de los tribunales españoles a lo que se le debe añadir el estado de alarma que hemos vivido que ha congestionado aún más los tribunales de nuestro país. La clara manifestación de la ralentización es que ha sido necesario que la Audiencia provincial revoque el auto y declare competente al Juzgado de Primera Instancia, de otro modo, hubiese sido el juez a quo quien hubiese resuelto el litigio directamente sin ser necesaria la incoación de otro proceso. Este desafortunado escenario es fácilmente evitable a través de una formación apropiada y completa de los operadores jurídicos, incluyendo a los jueces y tribunales españoles.

38. Es cierto que la Audiencia Provincial manifiesta un conocimiento más elevado de las fuentes de Derecho internacional privado, y puede señalarse que el resultado al que dirigen sus conclusiones son acertadas, sin embargo, yerra, como se refirió anteriormente, en declarar como aplicable el Convenio de la Haya de 1996. 
39. No es, ni ha sido, infrecuente la resolución de litigios de Derecho internacional privado de forma equívoca en la que, por ejemplo, se confundía un problema de competencia con otro de reconocimiento, o en la que se escogía mal el convenio aplicable o la norma aplicable al caso concreto.

40. Hace ya bastante tiempo que el Derecho internacional privado tiene la importancia que merecía desde antaño. Han sido la interdependencia y la globalización las que han provocado un aumento de las relaciones jurídicas con aspectos transfronterizos. Y ello, ineludiblemente, ha significado un incremento del surgimiento de conflictos en las relaciones jurídico privadas que requerían para su resolución la aplicación de las normas de Derecho internacional privado. En esta conclusión descansa la gran importancia de contar con una adecuada formación es aspectos de esta rama del Derecho. 